\title{
FUNGAL EPIDEMICS OF PLANTS
}

GINCE the autumn of 1958, when it was first noticed $S$ in England and the Netherlands, the fungus Perono. spora tabacina Adam. has been found attacking tobacco crops throughout Europe, in North Africa and deep into Asia. The rate at which this 'tobacco blue mould' has spread and the damage it has eaused have reminded agriculturists that fungi can cause epidemics among plants rivalling, both in extent and intensity, those caused recently in rabbits and man by the viruses of myxomatosis or Asian 'flu. To Europeans, tobaceo blue mould will probably seem to merit a place with potato blight, wheat stem rust and coffee rust, diseases that have altered the course of agriculture and of history. During recent decades, interest in the epidemiology of such fungal diseases has declined. This may partly be the result of changing fashions in science, but the success of plant broeders in producing disease-resistant varieties and chemists in producing effective fungicides is probably the main reason. The difficulty of maintaining disease resistance and an increasing awareness of the ecological complications of using plant-protective chemicals now seem likely to reawaken interest in the biology, multiplication and spread of the epidemic fungi.

The moment was therefore opportune for about fifty plant pathologists and meteorologists from twelve countries to meet at Pau, France, during the first two weeks of September to discuss the "Epidemiology and Biometeorology of Fungal Diseases of Plants". Their meeting, made possible by a generous grant from the Pure Science Bureau of the North Atlantic Treaty Organization, was held in conjunction with the third International Congress of Biometeorology. Although under the joint chairmanship of Prof. R. D. Schein, of Pennsylvania State University, and myself, Prof. Schein and the Conference Center of his university were chiefly responsible for the successful executive arrangements. A twelvemember committee helped to select a programme starting with an examination of the origin of epidemies, the infection requirements of pathogens and how best to make the needed biological and meteorological measurements, and proceeding from these foundations to consider the theory of epidemies, and how to forecast their development and issue spray warnings. This programme and the contributions of participants were circulated before the meeting in a 350-page book, so that much of the 56 hours of meetings could be spent in discussion.

Although fungi can be placed in broad groups according to their modes of perennation, almost every pathogen has some singular habits whereby it manages to survive the absence of hosts or their resistance during dormancy. Because the origin of each disease must be separately investigated the opportunity to exchange experience was particularly valuable, but makes it very difficult to summarize progress. Work described on diseases of perennial fruit crops showed how decreasing pathogen 'carry-over' facilitated and improved control, even when the disease was far from eliminated. Close study of the ecology of such pathogens has revealed how carry-over may be affected by important and quite unsuspected factors. The time seems overdue for a quantitative re-examination of factors controlling the survival of the relie sources from which many diseases of annual crops arise.

Quite different problems need solution to prevent annual introductions of diseases from a distance. Despite improvements in spore-trapping methods and many additions to our knowledge of how spore concentrations change with the weather and the time of day, it is still impossible to predict the chance and range of effective dispersal. Several theories have been proposed for estimating the track of the centre of an imaginary spore cloud or how its density declines with increasing distance from a source. Discussions of the relative merits of these theories and their present usefulness showed that, although enlightening, they are still far from comprehensive, and emphasized the need for experimental evidence illustrating the complexities of transport in the air. We must learn how to relate periodic spore liberation with ehanging turbulence, to estimate the frequency of trajectories allowing dispersal and the chance that spores will be prematurely deposited by precipitation.

Estimating spore concentrations is an improvement on recording eatches without reference to the volume of air sampled or trap efficieney, and may be adequate for investigations related to respiratory allergies, but it was agreed that the plant pathologist must strive eventually to measure the concentration of viable spores and to relate this to deposition and infection of susceptible plants. No one believed that this will be easy, or that present-day methods are adequate. At present the best evidence of long-distance transport of viable spores comes indirectly from the observed distribution of physiologic races of cereal rusts. Even if a high efficiency non-selective spore trap is developed to allow the routine culture of its catch at different times of day it will still be inadequate for obligate parasites. The complex deposition patterns of various-sized particles on such simple structures as microscope slides, and their possible redistribution by rain, suggest that this will not be easy. Furthermore. detailed microscopy of spores on leaf surfaces shows that the growth of those that penetrate is often nothing like that on the inert surfaces commonly used in germination tests.

Students of dispersal envied the preeision and environmental control possible in studying the infection processes of fungi, even though several artefacts reported showed that this also is difficult. However, refined methods of applying test inoculum were deseribed that allow precise examinations of the effects of dosage on the ratio of spores deposited to resulting lesions, of the interactions between crowded spores, and the intractable problem of the interaction between ontogeny and sus. ceptibility. Similarly, improved eontrolled-environment chambers have allowed experiments to be so amplified that minimum, optimum and maximum, the traditional cardinal points of growth response curves, are giving place to much more complete investigations of interacting factors, which, with the help of computers, will find their best expression in mathematical equations. Nevertheless, it was encouraging to find that, even before these constant-temperature rooms have yielded all their secrets, some participants already dissatisficd with the limitations they impose were determined to find better ways of estimating the response of organisms to various amplitudes of temperature cycles about the samo average. and also the effect of erratically fluctuating temperatures and whether the changes themselves have any significance.

Moisture probably limits the development of fungi that infect foliage more often than temperature does. Certainly this is true of most germinating spores, which need wet leaf surfaces on which to grow and penetrate their hosts. The duration of wetness on leaves or test surfaces is a parameter which has not concerned meteorologists but is important to plant pathologists. Various methods of measurement that have been used were discussed, and it was agreed that surfaces exposed freely, or even among the branches of orchard trees away from the steep mois- 
ture gradients near soil surfaces, remained wet for nearly the same time as standard climatological measurements indicated that relative humidity was at least 90 per cent. Among annual crops with dense foliage extending down to the soil, large differences occur in the persistence of water films at different heights and depend partly on whether the deposits result from rain or dew. A third source of water deposits is 'guttation'; its possible importanco was much discussed following a suggestion that water exuded at stomata was often the site of spore germination. Although this remains to be fully established, there was general agreement that guttation is too seldom measured and, on plants, is difficult to separate quantitatively from dew.

The biological foundations having been laid, the meteorologists played an increasing part in the discussions. Usually their approach had to be scaled-down to meet the biologists, who often started from the microseopic size of the pathogens, an exercise probably good for both groups. The biologists were guided through the intricacies of instrumentation, with many warnings of common inaccuracies; reminded of the wealth of past weather records and the information waiting in this treasure chest for anyone who can pose the right questions. The discussions ranged from the microscopic scale of radiation effects at all stages of the dispersal and infection processes, through microclimatology and the effect of local topography on air movement in calm conditions, to the characteristics and importance of various synoptic weather situations in favouring disease development.

Meteorologists, like biologists, are exponents of a still inexact science in which experience is important, but at this meeting their training helped them to guide biologists towards an understanding of the mathematical approach to the theory of epidemics. Despite their efforts, a gap still remained between mathematicians bent on wholesale integration and biologists still in the phase of patient analysis. In Nature, success is so often exceptional that many think attempts to define the average behaviour of a hypothetical pathogen are of limited usefulness while they still depend on so many reckless assumptions. How- ever, none seemed to doubt that the two schools must eventually be united and that such meetings are the best means of doing so.

The section concerned with the technicalities and practice of plant-disease forecasting provided a natural opportunity to synthesize most of the previous discussions. Contrasting the criteria used in various countries for a single disease stressed how different was the weather limiting fungal development in hot, cold, damp or arid climates and explained why meteorological forecast criteria are seldom applicable in all countries. Usually the development of diseases is predicted from recent weather. The feasibility of giving earlier or more precise spray warnings by using weather forecasts was considered but seemed limited, both by their inaccuracy and the time required to take action, to sounding an 'alert' when particularly careful spray timing is required.

There can be few examples where the 'end justifies the means' so often as when forecasts of plant diseases are accurate. Usually the forecasts are partly subjective, sometimes purely empirical or depending on associated but otherwise quite unrelated phenological happenings. Damage can be avoided by forecasting seed infection and then selecting stocks from healthy areas, or even by accelerating the development of symptoms on many harvested samples so that the least affected can be selected for longest storage. Most forecasters experienced difficulty in communicating with the public and in assess. ing the acceptance or the value of their predictions. There was therefore much admiration for the success attributed to warnings of vine mildew in North Italy, where the alarm given by ringing church bells had caused the wholesale abandonment of political meetings in favour of spraying machines.

It would be improper for me as one of the organizers to comment on the success of the meeting. Nevertheless, it was encouraging that a lively interest persisted to the end of the long programme and that participants left hoping that progress within the next five years would justify holding another meeting, probably in the Netherlands.

J. M. Hirst

\section{THE FAUNA PRESERVATION SOCIETY}

$\mathrm{O}^{\mathrm{N}}$ N December 16, the Fauna Preservation Society celebrated its diamond jubilee with a dinner in the rooms of the Zoological Society of London. During the sixty years of its existence the Society has been closely identified with most of the efforts which have been made to preserve and conserve the diminishing fauna of the world. In recent years the Society sponsored the survey of the Serengeti National Park in Tanganyika; it largely financed "Operation Noah", the animal rescue project at Kariba on the Zambesi and it sent an expedition to southern Arabia in what promises to be a successful effort to save the Arabian oryx from extinction.

Under a slightly different name, the Fauna Preservation Society was founded in 1903. In that year a number of people heard that the authorities in the Sudan were proposing to convert an important game reserve north of the Sobat on the Upper Nile into a hunting ground for serving officers. Protests were lodged. Thanks largely to the exertions of Mr. Edward Buxton, a deputation of distinguished men went to soe the Colonial Secretary. They included the Duke of Bedford, Lord Avebury, Sir Edward Grey, Prof. Ray Lankester, Mr. P. L. Selater and Mr. F. C. Selous. The reserve was saved. In a circular issued shortly afterwards, the members of the deputation said that their intervention seemed to be "a good example of bringing the public opinion of persons at home who are interested in the preservation of the fauna of Africa to the notice of officials on the spot. It seems desirable", they said, "that those who have taken an interest in the matter should continue to act together". They thought that "a small association should be formed for the purpose of disseminating among its members information which is to be found scattered in a great number of official reports and in other sources, dealing with game reserves, game laws, the amount of game killed, the gradual disappearance of species, etc.".

The association became the Society for the Preservation of the Wild Fauna of the Empire, and eventually, the Fauna Preservation Society. In many ways the Society's records reflect the changing history of man's attitude towards the rest of Nature. In 1906 Lord Cranworth reported that the Boers were slaughtering game on a prodigious scale, exporting the sun-dried flesh (biltong) and selling the hides and horns. Efforts were made to stop the killing. The Society was equally concerned about the threat to shoot wild animals to feed workmen engaged on the construction of the new railway to the Victoria Falls. Men of the calibre of Sir Harry Johnston and Major Stevenson-Hamilton, founder and later warden of the Kruger National Park, were quick to note danger to wild life, and the Society acted on their reports. Early in its existence (in 1906) the Society became deeply conscious of the significance of trypanosomiasis, the diseases of men and animals transmitted by tsetse flies, and urged 